\title{
Faire sens de l'absurde dans la bureaucratie kafkaïenne
}

Florence Allard-Poesi, \& Lorena Matos

Contexte et problématique : Comment les managers font-ils sens de l'absurde des organisations bureaucratiques dans lesquelles ils travaillent ? Avec quelles conséquences ? Cette recherche est née d'une étude quasi-ethnographique menée sur des projets de Recherche \& développement \& innovation dans une grande entreprise brésilienne du secteur électrique, recherche dans laquelle les responsables de projet interrogés qualifiaient leurs expériences au travail d'absurdes. Par-là, ils signifient que conformément aux règles du secteur et de l'organisation, ils doivent réaliser de nombreuses tâches dont ils savent qu'elles n'auront aucune conséquence pour l'organisation. $\mathrm{Si}$, dans la bureaucratie wébérienne, les règles et le formalisme font sens en ce qu'ils participent de la prédictibilité et de l'équité du système, les acteurs cherchent là vainement à trouver du sens à ce qu'ils font, rapprochant leurs expériences de celle du héros du château de Kafka.

Méthodologie: La recherche s'appuie sur des entretiens approfondis menés avec une cinquantaine de managers de projets et une présence prolongée dans l'entreprise.

Premiers résultats: Le sentiment de solitude et de culpabilité liée à la responsabilité, notamment financière qui incombe aux managers dans la gestion de leur projet, d'une part et l'absence de soutien hiérarchique, d'autre part ; ces résultats et leurs conséquences en termes de souffrance au travail sont discutés au regard des travaux sur les bureaucraties contemporaines.

Mots clés : Absurde ; Sens ; Kafka ; Bureaucratie. 